\title{
ARBORIZAÇÃO VIÁRIA DE CACHOEIRA DO SUL/RS: DIVERSIDADE, FITOGEOGRAFIA E CONFLITOS COM A INFRAESTRUTURA URBANA
}

Diogo de Souza Lindenmaier; Bernardo Sayão Penna e Souza ${ }^{2}$

\section{Resumo}

O presente estudo faz uma avaliação da diversidade arbórea e fitogeográfica das árvores presentes nas vias de Cachoeira do Sul, RS-Brasil, bem como uma sondagem de aspectos qualitativos referentes à integridade, manutenção e conflitos entre a vegetação viária e os equipamentos urbanos. Quinze ruas foram selecionadas para amostragem onde todos os indivíduos arbóreos com perímetro mínimo de $15 \mathrm{~cm}$ a altura do peito foram identificados. A diversidade foi estimada a partir da frequência de indivíduos por espécie e através do Índice de Shannon H'. A origem fitogeográfica de cada espécie foi examinada a partir de pesquisas bibliográficas e consultas a especialistas. As vias amostradas apresentaram 2.400 indivíduos distribuídos em 101 espécies, pertencentes a 36 famílias botânicas. As quatro espécies mais frequentes apresentaram densidade de $53,8 \%$ dos indivíduos totais. O Índice de Shannon H' foi de 3,14 nats/ind., e a Equabilidade de Pielou J' 0,68. Houve predominância de espécies exóticas, com 57,4\%, e em relação ao número de indivíduos, $61,7 \%$ pertenceram a espécies oriundas de outras partes do mundo. Quanto à fitossanidade da vegetação, 22,8\% apresentaram problemas. Os resultados obtidos apoiam pesquisas realizadas em diversas cidades brasileiras, que apontam um estado de homogeneidade florística, com utilização preponderante de espécimes exógenos, resultando em baixa diversidade.

Palavras-chave: Arborização urbana; Arborização de ruas; Conflitos em arborização

\section{PHYTOGEOGRAPHICAL AND ECOLOGICAL ASPECTS OF STREET ARBORIZATION OF CACHOEIRA DO SUL-RS-BRAZIL.}

\section{Abstract}

This study is an evaluation of tree diversity and phytogeographical trees present in the streets of Cachoeira do Sul/RS, Brazil, as well as a survey of qualitative aspects relating to health and road maintenance of vegetation. Fifteen streets were selected through aerial image where all trees with minimum perimeter of $15 \mathrm{~cm}$ at breast height were identified. Diversity was estimated from the frequency of individuals by species and by the Shannon index H'. The phytogeographic origin of each species was examined from literature searches and consultations with specialists. The routes had sampled 2400 individuals in 101 species belonging to 36 families. The four most frequent species showed density 53,8\% of total individuals. The Shannon Index H' was 3,14 nats/ind., and equability J' 0,68 . There was a predominance of exotic species, with $57,4 \%$, and compared the frequency of individuals, $61,7 \%$ belonged to species from other parts of the world. As the health of vegetation, $22,8 \%$ had problems. The results obtained here supports research in several Brazilian cities, which indicate a state of floristic homogeneity, with predominant use of exogenous specimens, resulting in low diversity of character.

Key words: Urban forestry; Streets trees; Conflicts in afforestation

\footnotetext{
${ }^{1}$ Mestrando do Programa de Pós-graduação em Geografia da Universidade Federal de Santa Maria - (bagualsilvestris@ibest.com.br)

${ }^{2}$ Professor Associado do Departamento de Geociências do CCNE/UFSM, professor do quadro permanente do PPGGeo -

(bernardosps@yahoo.com.br)

${ }^{3}$ recebido em 17.06.2012 e aceito para publicação em 15.03.2014
} 


\section{INTRODUÇÃO}

A qualidade ambiental urbana tem sido um tema recorrente nos debates sobre o futuro das cidades no Brasil e no mundo. A partir do ano de 2011, mais da metade da população mundial passou a viver em áreas urbanas, segundo relatório do UNFPA (2011). Em países em desenvolvimento o fluxo de migração para as cidades ainda é acentuado, no Brasil esse número chega a $84 \%$ da população vivendo em cidades (IBGE, 2011).

As cidades podem ser pensadas como paisagens onde diferentes elementos interagem de forma sistêmica, influenciando a conformação do mosaico urbano. Nesse contexto, a ação do homem, definida aqui como elemento antrópico, tem influência preponderante sobre os demais componentes do sistema urbano, transformando as cidades em espaços altamente complexos, completamente distintos dos ambientes naturais (CHRISTOFOLETTI, 1999).

Dentre os elementos que interatuam na conformação da paisagem urbana e influenciam de forma decisiva a qualidade ambiental, destaca-se a vegetação, e em particular as árvores. Esta temática tem sido abordada por diferentes disciplinas científicas, que ao avaliarem a questão acabam por usar categorias operacionais muitas vezes distintas entre si, gerando conflitos conceituais (LOBODA e ANGELIS, 2005). A partir de adaptações às classificações propostas por Lima et al. (1994), Cavalheiro et al. (1999), Santos e Teixeira, 2001, Daltoé et al. (2004), Gonçalves e Paiva (2004), Magalhães (2006) e Buccheri Filho (2006), e conforme o espaço que a arborização ocupa na cidade em maior escala, pode-se classificá-la como: a) Áreas verdes, que correspondem a espaços públicos ou privados de livre acesso, como parques, praças, campings, entre outros; Florestas urbanas, como sendo os remanescentes florestais inclusos dentro das cidades; Arborização de quintais $e$ jardins, em geral, presentes em residências ou em áreas privadas como condomínios e indústrias; e Arborização viária, que consiste na vegetação presente ao longo das ruas, canteiros centrais e rotatórias.

A arborização dentro do espaço urbano apresenta funcionalidades importantes na melhoria da qualidade ambiental. Auxiliam na manutenção do equilíbrio térmico por meio do sombreamento do solo impermeabilizado, atuando na reflectância e absorvância da radiação eletromagnética incidente, bem como atua no controle da umidade em baixa atmosfera através da evapotranspiração. O conjunto da vegetação, independente do espaço que ocupe nas cidades, ameniza a formação de ilhas de calor, fenômeno típico de ambientes urbanos (SHINZATO, 2009).

Pode-se destacar ainda, a importância da vegetação arbórea como elemento de função ecológica, estética, paisagística, psicológica e recreativa, sendo seu planejamento importante a fim de tornar a paisagem urbana menos artificial. A vegetação também contribui para a redução da poluição atmosférica por gases e particulados, e igualmente serve de barreira de contenção a ondas sonoras e ruídos. Exerce ainda, efeito tampão sobre a incidência de chuvas fortes que podem causar enxurradas e erosão dos solos (GÊISER et al., 1976; LIMA et al., 1994; DEMATTÊ, 1997). 
Para que a vegetação urbana desempenhe suas potenciais funcionalidades é necessário além de sua implementação, que seu planejamento leve em consideração aspectos relacionados à diversidade e origem fitogeográfica das espécies a serem utilizadas. Santamour Júnior (1990), no que diz respeito à diversidade arbórea, recomenda não se exceder mais que $10 \%$ de indivíduos por espécie, $20 \%$ de algum gênero e 30\% de uma família botânica. Essas recomendações se fundamentam com base na incidência de problemas ecológicos e epidêmicos.

Diversos autores, como cita Blum et al. (2008), têm apontado o uso acentuado de espécies exóticas, algumas das quais tóxicas, e em frequências elevadas quando comparadas a espécies nativas. O uso de espécies regionais na arborização urbana fundamenta-se na premissa de incorporar à cidade essências vegetais (arbórea) nativas, dispondo-as dentro do espaço urbano a fim de equacionar esse ecossistema artificializado, e proporcionar à sociedade maior qualidade ambiental, fator importante à qualidade de vida. (ISERNHAGEN et al., 2009).

A arborização de vias públicas pode atuar interconectando espaços urbanos como áreas verdes, remanescentes florestais, quintais e jardins, formando corredores capazes facilitar o fluxo da fauna e da flora desses ambientes (RACHID, 1999; SANTOS \& TEIXEIRA, 2001; PAIVA \& GONÇALVES, 2002; MENEGUETTI, 2003).

Através de levantamento e descrição da vegetação arbórea das vias públicas de Cachoeira do Sul-RS, o presente estudo objetivou: 1) conhecer a composição florística; 2) avaliar a origem fitogeográfica de espécies e indivíduos; 3) estimar a diversidade arbórea; 4) examinar as condições de sanidade dos vegetais como a ocorrência de podas e doenças, e 5) verificar a ocorrência de confronto entre as árvores e o pavimento dos passeios.

\section{MATERIAIS E MÉTODOS}

Área do estudo - A cidade de Cachoeira do Sul está localizada à margem esquerda do Rio Jacuí, na região fisiográfica denominada Depressão Central do Estado do Rio Grande do Sul (Figura 1). Foi o quinto município a ser fundado no Rio Grande do Sul, tendo seu povoamento iniciado por volta de 1769.

O município apresenta atualmente, segundo o senso 2010 do IBGE, uma população de 83.827 habitantes. Desses, 71.700 residem na área urbana, distribuídos em 34.639 domicílios. Entretanto, a população já contabilizou mais de 90.000 habitantes no início dos anos sessenta. Essa dinâmica negativa nos números demográficos é explicada por emancipações de distritos, sucessivas crises no setor produtivo, bem como fatores socioculturais que estimularam a emigração a partir dos anos setenta até atualidade (IBGE, 2011).

No que se refere a aspectos naturais, a cidade encontra-se inserida entre três formações vegetacionais distintas: campos (pampa); áreas de tensão ecológica; e remanescentes de floresta estacional decidual (aluvial), ao longo das margens dos afluentes do Rio Jacuí. (TEIXEIRA et al., 1986; MALUF et al., 1994) 
Figura 1. Localização da área urbana de Cachoeira do Sul/RS-Brasil

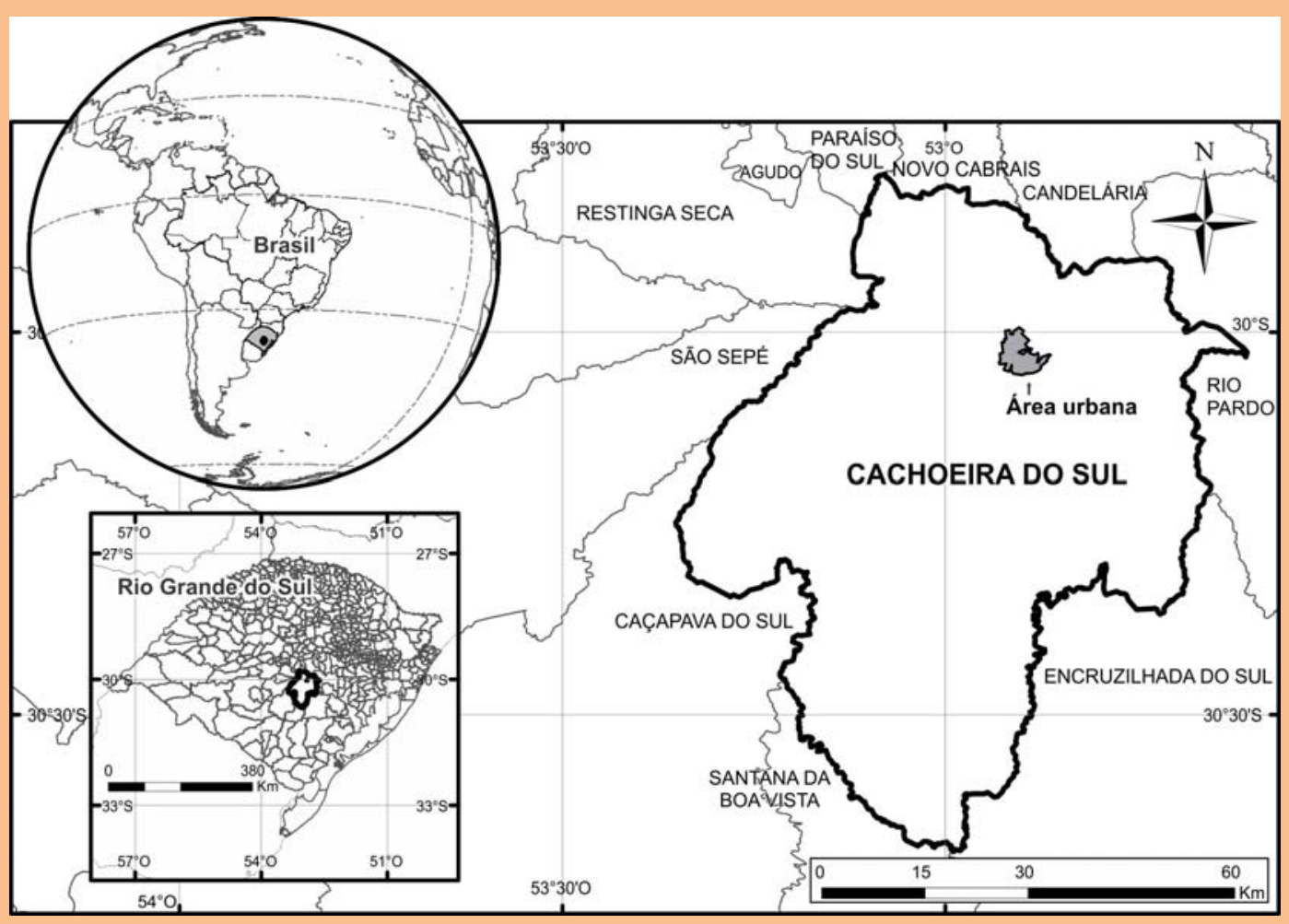

Na área urbana os solos de modo geral são profundos e bem drenados e sua morfoestrutura está relacionada à dinâmica sedimentar do rio Jacuí (JUSTUS et al., 1986). Suas cotas altimétricas encontram-se entre $26 \mathrm{~m}$ e $120 \mathrm{~m}$ de altitude, com relevo levemente ondulado.

O clima na região é considerado subtropical úmido, sem período seco definido, do tipo Cfa, segundo a classificação de Köppen. Estima-se uma precipitação média em torno de 1.594 mm/ano. A temperatura média anual é de $19,2^{\circ} \mathrm{C}$, sendo a média do mês mais quente superior a $24^{\circ} \mathrm{C}$ e a média do mês mais frio em torno de $13^{\circ} \mathrm{C}$ (IPAGRO, 1992).

Coleta dos dados - Neste estudo considerou-se arborização viária “toda a vegetação de porte arbóreo inserida no espaço correspondente a passeios, canteiros e rotatórias que acompanham a vias de tráfego da cidade”. Com auxílio de imagem aérea foram selecionadas ruas a serem inventariadas dentro do espaço urbano da cidade. Como critério de escolha dos pontos de amostragem, optou-se por cobrir de modo homogêneo o espaço urbano, elencando ruas em diferentes pontos da cidade. As ruas selecionadas para amostragem foram: Ernesto Pertile, Gregório da Fonseca, Marechal Hermes, Dom Pedro II, Olindo Scarparo, Dona Hermínia, Dom Pedrito, Aníbal Loureiro, Aparício Borges, Juvêncio Soares, João Neves da Fontoura, Conde de Porto Alegre, Horácio Borges, João Carlos Gaspary e Ricardo Schaurich (Figura 2).

Os trabalhos de campo para coleta dos dados foram realizados entre novembro de 2011 e fevereiro de 2012. Foram inventariados todos os indivíduos 
arbóreos com perímetro mínimo de $15 \mathrm{~cm}$ a altura do peito, presentes dentro do espaço correspondente as vias públicas. Indivíduos entouceirados com no mínimo $3 \mathrm{~m}$ de altura foram incluídos na amostragem. Foram incluídos no inventário também espécies da família Arecaceae.

Figura. 2. Imagem aérea com a localização dos pontos amostrais na paisagem urbana de Cachoeira do Sul/RS. As linhas em amarelo indicam as ruas amostradas. Fonte: Adaptada de Google Earth ${ }^{\mathrm{TM}}$ Mapping Service, 2012

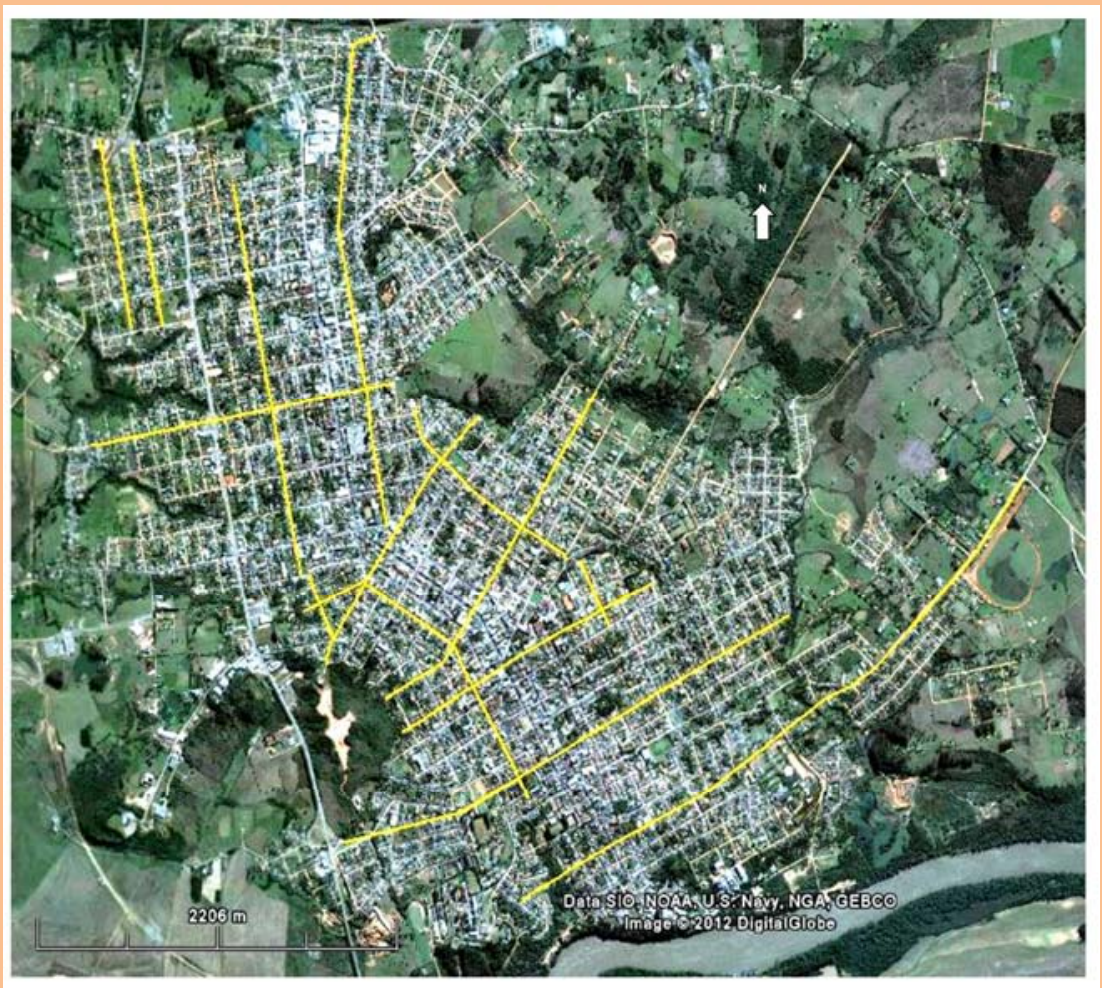

Cada indivíduo arbóreo amostrado teve coletado dados indicativos de qualidade e sanidade vegetal como ocorrência de podas drásticas, presença de parasitas, conflitos relacionados ao sistema radicular e os passeios e doenças.

As espécies arbóreas conhecidas foram identificadas in loco ou através de consulta ao banco de dados W3Tropicos do Missouri Botanical Garden. Espécies nativas tiveram identificação determinada através de comparação com material do herbário ICN-UFRGS e consulta ao banco de dados Flora Digital do Rio Grande do Sul. As famílias botânicas foram agrupadas de acordo com as recomendações do APG III (Angyosperm Phylogeny Group, 2009).

A diversidade arbórea das vias públicas foi estimada a partir da relação de abundância e frequência de indivíduos por espécies, e através da aplicação dos índices de diversidade de Shannon H' e Equabilidade de Pielou J', obtidos com auxílio do aplicativo PAST ver. 1.37, 2005.

A origem fitogeográfica de cada espécie foi examinada a partir de pesquisas bibliográficas e consultas aos bancos de dados Flora Digital do Rio Grande do Sul e W3Tropicos do Missouri Botanical Garden. Foram consideradas nativas aquelas 
espécies originárias de formações vegetais ocorrentes no Brasil, que não apresentam ocorrência natural na região do estudo. Foram consideradas nativas/regionais (NR) espécies cujos ecossistemas estejam representados na região sul do Brasil, sendo a espécie citada como ocorrente na região onde está a área do estudo. As espécies que são naturais de outros ecossistemas diferentes dos que ocorrem em território brasileiro foram consideradas exóticas (ISERNHAGEN et al., 2009).

\section{RESULTADOS E DISCUSSÃO}

As quinze ruas inventariadas totalizaram 22.574 metros de vias estudadas, onde foram identificados um total de 2400 indivíduos arbóreos pertencentes a
101 espécies, distribuídas em 86 gêneros e 35 famílias botânicas. Três indivíduos não foram identificados e 46 deles estavam mortos (Tabela 1).

Tabela 1. Famílias, espécies, abundância absoluta (A), abundância relativa (AR), frequência absoluta (FA), frequência relativa (FR) e origem fitogeográfica das espécies (OR) arbóreas amostradas nas vias da cidade de Cachoeira do Sul/RS. (Origem: E= exótica, N= nativa, NR= nativa regional)

\begin{tabular}{|c|c|c|c|c|c|c|}
\hline Família & Espécie & A & AR\% & $\mathbf{F}$ & FR\% & OR \\
\hline \multirow{2}{*}{ Anacardiaceae } & Mangifera indica L. & 2 & 0,08 & 2 & 13,3 & $E$ \\
\hline & Schinus terebinthifolius Raddi & 40 & 1,66 & 11 & 73,3 & NR \\
\hline Annonaceae & Annona neosalicifolia H. Hainer. & 5 & 0,20 & 5 & 33,3 & NR \\
\hline \multirow{4}{*}{ Apocynaceae } & Nerium oleander L. & 4 & 0,16 & 4 & 26,6 & $E$ \\
\hline & Plumeria rubra L. & 3 & 0,12 & 3 & 20,0 & $\mathrm{E}$ \\
\hline & Tabernaemontana catharinensis A. DC. & 1 & 0,04 & 1 & 6,6 & NR \\
\hline & Thevetia peruviana (Pers.) K. Schum. & 12 & 0,50 & 9 & 60,0 & $E$ \\
\hline Araliaceae & Schefflera actinophylla (Endl.) Harms. & 1 & 0,04 & 1 & 6,6 & $\mathrm{E}$ \\
\hline Araucariaceae & Araucaria angustifolia (Bertol.) Kuntze & 1 & 0,04 & 1 & 6,6 & NR \\
\hline \multirow{4}{*}{ Arecaceae } & $\begin{array}{l}\text { Archontophoenix cunninghamii H. Wendl. } \\
\text { \& Drude }\end{array}$ & 1 & 0,04 & 1 & 6,6 & $\mathrm{E}$ \\
\hline & Butia capitata (Mart.) Becc. & 3 & 0,08 & 3 & 20,0 & NR \\
\hline & Syagrus romanzoffiana (Cham.) Glassman & 15 & 0,62 & 5 & 33,3 & NR \\
\hline & Washingtonia robusta $\mathrm{H}$. Wendl. & 6 & 0,25 & 1 & 6,6 & $\mathrm{E}$ \\
\hline \multirow{3}{*}{ Asparagaceae } & Cordyline terminalis (L.) Kunth & 2 & 0,08 & 3 & 20,0 & $\mathrm{E}$ \\
\hline & Dracaena marginata Hort. & 2 & 0,08 & 2 & 13,3 & $\mathrm{E}$ \\
\hline & Yucca elephantipes Regel & 6 & 0,25 & 4 & 26,6 & $\mathrm{E}$ \\
\hline \multirow{6}{*}{ Bignoniaceae } & Jacaranda mimosifolia D. Don & 68 & 2,83 & 15 & 100 & $\mathrm{E}$ \\
\hline & Handroanthus albus (Cham.) Mattos & 37 & 1,54 & 14 & 93,3 & $\mathrm{~N}$ \\
\hline & $\begin{array}{l}\text { Handroanthus chrysotrichus (Mart. ex A. } \\
\text { DC.) Mattos }\end{array}$ & 305 & 12,7 & 15 & 100 & $\mathrm{~N}$ \\
\hline & Handroanthus heptaphyllus (Vell.) Mattos & 34 & 1,41 & 13 & 86,6 & NR \\
\hline & Handroanthus roseo-albus (Ridl.) Mattos & 1 & 0,04 & 1 & 6,6 & $\mathrm{~N}$ \\
\hline & Spathodea campanulata P. Beauv. & 21 & 0,87 & 8 & 53,3 & $\mathrm{E}$ \\
\hline Boraginaceae & Cordia trichotoma (Vell.) Arráb. ex Steud. & 1 & 0,04 & 1 & 6,6 & NR \\
\hline
\end{tabular}




\begin{tabular}{|c|c|c|c|c|c|c|}
\hline & $\begin{array}{l}\text { Cordia americana (L.) Gottshling \& } \\
\text { J.E.Mill. }\end{array}$ & 2 & 0,08 & 2 & 13,3 & NR \\
\hline Cannabaceae & Trema micrantha (L.) Blume & 1 & 0,04 & 1 & 6,6 & NR \\
\hline Caricaceae & Carica papaya L. & 2 & 0,08 & 2 & 20,0 & NR \\
\hline \multirow[t]{2}{*}{ Cupressaceae } & Cupressus cf.sempervirens L. & 9 & 0,37 & 7 & 13,3 & $E$ \\
\hline & Thuya occidentalis L. & 7 & 0,29 & 3 & 20,0 & $\mathrm{E}$ \\
\hline Ebenaceae & Diospyros kaki Thumb. & 1 & 0,04 & 1 & 6,6 & $E$ \\
\hline \multirow{2}{*}{ Euphorbiaceae } & Euphorbia cotinifolia L. & 1 & 0,04 & 1 & 6,6 & $\mathrm{E}$ \\
\hline & Manihot esculenta Krantz & 3 & 0,12 & 3 & 20,0 & $\mathrm{~N}$ \\
\hline \multirow{19}{*}{ Fabaceae } & Acacia podalyriaefolia A. Cunn. & 3 & 0,12 & 2 & 13,3 & $\mathrm{E}$ \\
\hline & Bauhinia forficata Link & 8 & 0,33 & 2 & 13,3 & NR \\
\hline & Bauhinia variegata L. & 21 & 0,87 & 7 & 46,6 & $\mathrm{E}$ \\
\hline & Caesalpinia leiostachya (Benth.) Duke & 1 & 0,04 & 1 & 6,6 & NR \\
\hline & Caesalpinia pluviosa DC. & 76 & 3,16 & 14 & 93,3 & NR \\
\hline & Calliandra brevipes Benth. & 4 & 0,16 & 2 & 13,3 & NR \\
\hline & Cassia fistula L. & 7 & 0,29 & 5 & 33,3 & $\mathrm{E}$ \\
\hline & Delonix regia (Bojer ex Hook.) Raf. & 10 & 0,41 & 6 & 40,0 & $\mathrm{E}$ \\
\hline & $\begin{array}{l}\text { Enterolobium contortisiliquum (Vell.) } \\
\text { Morong }\end{array}$ & 4 & 0,16 & 2 & 13,3 & NR \\
\hline & Erythrina crista-galli L. & 1 & 0,04 & 1 & 6,6 & NR \\
\hline & Inga marginata Kunth & 146 & 6,08 & 15 & 100 & NR \\
\hline & Inga vera Kunth & 4 & 0,16 & 4 & 26,6 & NR \\
\hline & Leucaena leucocephala (Lam.) de Wit & 3 & 0,12 & 3 & 20,0 & $\mathrm{E}$ \\
\hline & Paraptadenia rigida (Benth.) Brenan. & 4 & 0,16 & 3 & 20,0 & NR \\
\hline & Peltophorum dubium (Spreg.) Taub. & 53 & 2,20 & 12 & 80,0 & NR \\
\hline & Schizolobium parahyba (Vell.) S. F. Blake & 5 & 0,20 & 1 & 6,6 & $\mathrm{~N}$ \\
\hline & $\begin{array}{l}\text { Senna macranthera (DC. ex Collad.) H.S. } \\
\text { Irwin \& Barneby }\end{array}$ & 18 & 0,75 & 9 & 60,0 & $\mathrm{~N}$ \\
\hline & $\begin{array}{l}\text { Senna multijuga (Rich.) H.S. Irwin \& } \\
\text { Barneby }\end{array}$ & 11 & 0,45 & 8 & 53,3 & $\mathrm{~N}$ \\
\hline & Tipuana tipu Benth. Kuntze & 22 & 0,91 & 6 & 40,0 & $\mathrm{E}$ \\
\hline Junglandaceae & Carya illinoensis (Wang.)Kock & 6 & 0,25 & 6 & 40,0 & $\mathrm{E}$ \\
\hline \multirow{3}{*}{ Lauraceae } & Cinnamomum zeylanicum Blume & 47 & 1,95 & 15 & 100 & $\mathrm{E}$ \\
\hline & Nectandra megapotamica (Spreng.) Mez & 3 & 0,12 & 3 & 20,0 & NR \\
\hline & Persea americana Mill. & 4 & 0,16 & 4 & 26,6 & $\mathrm{E}$ \\
\hline Lythraceae & Lagerstroemia indica $\mathrm{L}$. & 512 & 21,3 & 15 & 100 & $\mathrm{E}$ \\
\hline \multirow{3}{*}{ Magnoliaceae } & Magnolia champaca L. & 3 & 0,12 & 2 & 13,3 & $\mathrm{E}$ \\
\hline & Magnolia liliflora Desr & 1 & 0,04 & 1 & 6,6 & $\mathrm{E}$ \\
\hline & Magnolia ovata (A. St.-Hil.) Spreng. & 1 & 0,04 & 1 & 6,6 & $\mathrm{~N}$ \\
\hline \multirow{6}{*}{ Malvaceae } & $\begin{array}{l}\text { Brachychiton populneus (Schott \& Endl.) } \\
\text { R. Br. }\end{array}$ & 4 & 0,16 & 3 & 20,0 & E \\
\hline & Ceiba speciosa (A. St.-Hil.) Ravenna & 2 & 0,08 & 1 & 6,6 & $\mathrm{~N}$ \\
\hline & Dombeya wallichii ( Lindl.) K. Schum. & 4 & 0,16 & 1 & 6,6 & $\mathrm{E}$ \\
\hline & Hibiscus rosa-sinensis L. & 30 & 1,25 & 11 & 73,3 & $\mathrm{E}$ \\
\hline & Luehea divaricata Mart. & 3 & 0,12 & 3 & 20,0 & NR \\
\hline & Pachira glabra Pasq. & 1 & 0,04 & 1 & 6,6 & $\mathrm{E}$ \\
\hline Melastomataceae & Tibouchina granulosa (Ders.) Cogn. & 9 & 0,37 & 6 & 40,0 & $\mathrm{~N}$ \\
\hline iaceae & Melia azedarach L. & 69 & 2,87 & 13 & 86,6 & $\mathrm{E}$ \\
\hline \multirow{3}{*}{ Moraceae } & Ficus benjamina L. & 30 & 1,25 & 10 & 66,6 & $\mathrm{E}$ \\
\hline & Ficus benjamina L. var. variegata & 10 & 0,41 & 6 & 40,0 & $\mathrm{E}$ \\
\hline & Morus nigra L. & 24 & 1,00 & 11 & 73,3 & $\mathrm{E}$ \\
\hline \multirow{4}{*}{ Myrtaceae } & Callistemon speciosus (Sims) DC. & 20 & 0,83 & 6 & 40,0 & E \\
\hline & Eugenia involucrata DC. & 6 & 0,25 & 5 & 33,3 & NR \\
\hline & Eugenia uniflora L. & 28 & 1,16 & 12 & 80,0 & NR \\
\hline & Myrcianthes pungens (O. Berg.) D. & 8 & 0,33 & 6 & 40,0 & NR \\
\hline
\end{tabular}




\begin{tabular}{|c|c|c|c|c|c|c|}
\hline & Legrand & & & & & \\
\hline & Myrciaria cauliflora (Mart.) O. Berg. & 1 & 0,04 & 1 & 6,6 & $\mathrm{~N}$ \\
\hline & $\begin{array}{l}\text { Psidium cattleyanum var. coriaceum } \\
\text { (Mart. ex O. Berg) Kiaersk. }\end{array}$ & 12 & 0,50 & 7 & 46,6 & $\mathrm{~N}$ \\
\hline & Psidium guajava L. & 12 & 0,50 & 8 & 53,3 & $\mathrm{E}$ \\
\hline & Syzygium cumini (L.) Skeels & 20 & 0,83 & 11 & 73,3 & $\mathrm{E}$ \\
\hline & Myrtaceae 1 & 2 & 0,08 & 2 & 13,3 & $\mathrm{E}$ \\
\hline Oleaceae & Ligustrum lucidum W. T. Aiton & 330 & 13,7 & 15 & 100 & $\mathrm{E}$ \\
\hline Oxalidaceae & Averrhoa carambola L. & 1 & 0,04 & 1 & 6,6 & $\mathrm{E}$ \\
\hline Platanaceae & Platanus occidentalis L. & 1 & 0,04 & 1 & 6,6 & $\mathrm{E}$ \\
\hline Pinaceae & Pinus taeda L. & 1 & 0,04 & 1 & 6,6 & $\mathrm{E}$ \\
\hline Proteaceae & Grevillea robusta A. Cunn. ex R. Br. & 5 & 0,20 & 3 & 20,0 & $\mathrm{E}$ \\
\hline Rhamnaceae & Hovenia dulcis Thunb. & 11 & 0,45 & 9 & 60,0 & $\mathrm{E}$ \\
\hline \multirow{4}{*}{ Rosaceae } & Eriobotrya japonica (Thunb.) Lindl. & 6 & 0,25 & 5 & 33,3 & $\mathrm{E}$ \\
\hline & Prunus domestica L. & 3 & 0,12 & 2 & 13,3 & $\mathrm{E}$ \\
\hline & Prunus persica (L.) Batsch. & 1 & 0,04 & 1 & 6,6 & $\mathrm{E}$ \\
\hline & Pyrus communis L. & 2 & 0,08 & 1 & 6,6 & $\mathrm{E}$ \\
\hline \multirow{3}{*}{ Rutaceae } & Citrus spp. & 56 & 2,33 & 13 & 86,6 & $\mathrm{E}$ \\
\hline & Murraya paniculata (L.) Jack & 11 & 0,45 & 7 & 46,6 & E \\
\hline & Zanthoxylum hyemale A. St.-Hil. & 3 & 0,12 & 1 & 6,6 & NR \\
\hline \multirow{4}{*}{ Salicaceae } & Casearia sylvestris Sw. & 3 & 0,12 & 3 & 20,0 & NR \\
\hline & Populus alba L. & 4 & 0,16 & 3 & 20,0 & $\mathrm{E}$ \\
\hline & Salix babylonica L. & 3 & 0,12 & 3 & 20,0 & $\mathrm{E}$ \\
\hline & Salix humboldtiana Andersson & 2 & 0,08 & 1 & 6,6 & NR \\
\hline \multirow[b]{2}{*}{ Sapindaceae } & Acer palmatum Raf. & 5 & 0,20 & 5 & 33,3 & $\mathrm{E}$ \\
\hline & $\begin{array}{l}\text { Allophylus edulis (A. St.-Hil., Cambess. \& } \\
\text { A. Juss.) Radlk. }\end{array}$ & 4 & 0,16 & 3 & 20,0 & NR \\
\hline \multirow[b]{2}{*}{ Solanaceae } & Brunfelsia uniflora (Pohl) D. Don. & 3 & 0,12 & 3 & 20,0 & $\mathrm{~N}$ \\
\hline & Solanum mauricianum Scop. & 1 & 0,04 & 1 & 6,6 & NR \\
\hline \multirow[t]{4}{*}{ Verbenaceae } & Duranta rapens L. & 25 & 1,04 & 4 & 26,6 & $\mathrm{E}$ \\
\hline & Indeterminada 1 & 1 & 0,04 & 1 & 6,6 & \\
\hline & Indeterminada 2 & 1 & 0,04 & 1 & 6,6 & \\
\hline & Indivíduos mortos & 46 & 1,91 & 14 & 93,3 & \\
\hline
\end{tabular}

O indicador de suficiência amostral para o inventário das vias foi obtido através da técnica de rarefação, que indicou a estabilização na curva de acúmulo de espécies (Fig. 3). Em ambientes relativamente homogêneos como as cidades, a técnica de acumulação de espécies indica com segurança se o esforço de amostragem é satisfatório, ou se será necessário amostragens adicionais onde poderiam aparecer novas espécies. Ao contrário de florestas naturais que apresentam padrões variados de distribuição espacial das populações, em meio urbano o indicador de suficiência é eficiente para saber se a amostragem realizada é representativa e reflete com maior precisão a riqueza vegetal no conjunto da arborização das ruas.

Para gerar o Índice de Abundância, que corresponde à densidade de elementos arbóreos por espaço linear de rua, utilizou-se nesse caso apenas os dados relativos a um lado da via. O índice estimado foi de 53,15 árvores/Km de via, valor considerado alto quando comparado a demais estudos realizados no Brasil. Em Campos do Jordão/SP, por exemplo, Andrade (2002) registrou um índice de 17,22 árvores/Km, tendo este inventariado $48.544 \mathrm{~m}$ de ruas onde encontrou somente 836 indivíduos. Na cidade de Colorado/RS o índice de abundância foi de 43 árvores/Km 
(RABER e REBELATO, 2010). Rachid e Couto (1999), encontraram 2.958 elementos (plantas vivas, plantas mortas e covas abertas) num total de 98,21 km de calçada e, com essa amostra, obteve-se uma estimativa de 30,12 árvores/Km de calçada.

Esse índice é utilizado para representar o adensamento de árvores ao longo dos passeios, e não há até o momento um número considerado ideal, ou recomendável. Sua utilização em nível de pesquisa baseia-se em comparações com outros estudos, e sua aplicação ganha relevância pelos projetos de manejo. Analisado de forma isolada, sem o cruzamento de dados qualitativos, o índice pouco acrescenta à compreensão da realidade na arborização viária.

Figura 3. Curva de acumulação de espécies do inventário da arborização viária de Cachoeira do Sul/RS, 2012

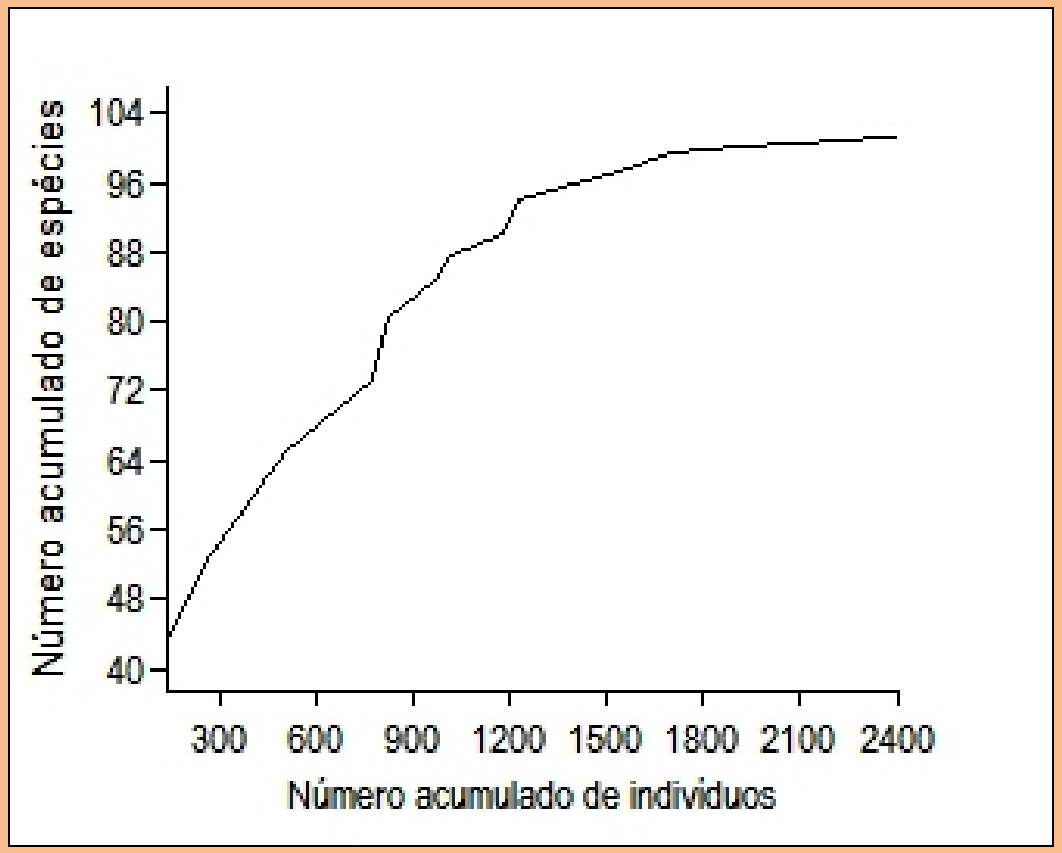

As famílias que apresentaram maior riqueza de espécies foram: Fabaceae com 19 espécies, Myrtaceae com 10, Bignoniaceae e Malvaceae com seis espécies cada uma. Na relação, abundância de indivíduos por família, $80 \%$ do número total de exemplares pertenceram a apenas 6 famílias (Tab. 1).

Diversos estudos sobre arborização viária e áreas verdes realizados no Brasil apontam a família Fabaceae como o principal táxon tanto em riqueza de espécies, quanto em número de indivíduos (RUSCHEL e LEITE, 2002; SOUZA et al., 2004; KURIHARA et al., 2005; CORREIA, 2006;
RABER, 2010; ANDREATTA et al., 2011). As famílias Myrtaceae, Bignoniaceae e Rutaceae também apresentaram destaque. Todas essas famílias, além de outras importantes que não foram mencionadas aqui (Tabela 1), são amplamente utilizadas, e ao que tudo indica, são cultivadas por apresentarem estruturas de valor estético (flores, folhas, frutos...) e padrões paisagísticos desejáveis (SOUZA e LORENZI, 2005).

Das 101 espécies identificadas ocupando o espaço dos passeios nas ruas amostradas em Cachoeira do Sul, 4 espécies perfizeram 53,8\% do total de indivíduos amostrados, são elas: Lagerstroemia 
indica, Ligustrum lucidum, Handroanthus chrysotrichus e Inga marginata (Tabela 1).

A riqueza florística no presente estudo pode ser considerada alta quando comparada a demais estudos realizados no Sul do Brasil. Em Porto Alegre, Salvi et al., (2011) registraram 61 espécies. Na cidade de Santa Maria/RS, Andreatta et al., (2011) encontraram 95 espécies em amostragem nas ruas da cidade. Canoas/RS apresentou 73 espécies arbóreas distribuídas nos passeios de bairros nobres e bairros periféricos (CORREIA, 2006). Em Lajeado/RS foram 69 espécies (RUSCHEL e LEITE, 2002), e em Colorado/RS foram identificadas 45 espécies nas ruas da pequena cidade (RABER, 2010). Lindenmaier e Santos (2008), em inventário realizado nas áreas verdes da mesma cidade do presente estudo encontraram 132 táxons. Souza et al., (2004) encontraram 75 espécies na arborização da cidade de Jaú/SP. Em Bocaína-SP, Marques (2005) identificou 60 espécies nas vias públicas da cidade. Em Campos do Jordão/SP, Andrade (2002) registrou 32 espécies (apud ISERNHAGEN, 2009).

O número de espécies pode variar significativamente entre cidades, independendo da condição demográfica ou da localização geográfica. Essa variação nem sempre revela menor ou maior diversidade, dependendo esse caráter, em maior escala, de aspectos florísticos como a abundância de indivíduos por espécie e das relações fitogeográficas dos seus componentes. Os padrões de riqueza e diversidade da arborização viária das cidades são fortemente influenciados pelo que se convencionou chamar de "fator antrópico", que se referem às ações do poder público como projetos de arborização, e também, através de ações individuais dos cidadãos que comumente plantam árvores em frente a suas residências.
Do número total de espécies observadas, 57 eram exóticas, originárias de outras regiões naturais do mundo, o que corresponde a 56,4\% do total. As nativas perfizeram 14 espécies (13,8\%), e as nativas regionais (NR) registraram 30 espécies (29,7\%). Em relação ao número de indivíduos, de 2400 árvores amostradas, $61,7 \%$ são exóticas; $17 \%$ são nativas e 19,3\% são nativas regionais. Algumas espécies citadas para o Rio Grande do Sul, porém, sem ocorrência nas florestas da região central do Estado, como o caso de Ceiba speciosa e Magnolia ovata, foram consideradas apenas nativas. Através dos dados nota-se o predomínio de elementos exóticos tanto em número de espécies, quanto em abundância de indivíduos.

O uso intensivo de espécies exóticas ainda é uma representação de padrões paisagísticos pretéritos, onde se valorizavam os atributos mais excêntricos das espécies e a primazia por passeios e aleias com arborização homogênea. O paradigma atual em arborização urbana, tanto na vegetação viária quanto em áreas verdes, indica a emergência de um modelo chamado “ecossistêmico” (JOSAFA, 2008), onde o fator estético deixa de ser privilegiado, e as potenciais funcionalidades ambientais da vegetação dentro do sistema urbano passam a ser a ideia central. Entretanto, não se deve subestimar o uso de espécies exóticas na arborização viária, uma vez que o ambiente dos passeios é extremamente restritivo, nos quais muitas espécies florestais nativas não conseguem se desenvolver.

Em relação a estimativas de diversidade, a espécie de maior frequência, $L$. indica, registrou 21,3\% do número total de indivíduos, o que significa 512 exemplares de um universo amostral de 2400 indivíduos. As quatro espécies mais abundantes somaram juntas 50,54\% dos indivíduos totais. Em outro extremo, houve um considerável índice de 
espécies que apresentaram somente um indivíduo, 19,8\% do total (Tabela 1).

A diversidade arbórea em áreas urbanas tem sido uma questão central em diversos estudos sobre arborização no Brasil, e seu caráter é associado à qualidade ambiental urbana. A medida mais utilizada em estudos para descrever a diversidade vegetal no espaço urbano é a abundância de indivíduos por espécie. Grey e Deneke (1978) recomendam $10 \%$ de indivíduos para uma população arbórea em área urbana. Este índice baseia-se principalmente em questões fitossanitárias.

Santamour Júnior (1990) recomenda 10\% de frequência para uma espécie, 20\% para o algum gênero e 30\% para uma família. Para a vegetação viária de Cachoeira do Sul/RS o presente estudo encontrou 3 espécies com elevada abundância e frequência, Ligustrum lucidum, Lagerstroemia indica e Handroanthus chrysotrichus com abundância relativa superior a $10 \%$. Consequentemente, o gênero Lagerstroemia apresentou frequência superior a 20\%, entretanto, nenhuma das famílias excedeu a frequência de 30\%. Já Milano e Dalcin (2000) recomendam um índice ótimo de frequência por espécie entre $10 \%$ e $15 \%$.

Para se ter uma melhor noção do caráter de diversidade, pode-se ainda relacionar a abundância de indivíduos à origem fitogeográfica das espécies. Embora a riqueza de espécies encontradas na arborização viária de Cachoeira do Sul possa ser considerada alta, mais da metade das espécies $(57,4 \%)$ são oriundas de outras regiões naturais do mundo, logo apresentam um potencial ecológico menor quando comparado a espécies de ocorrência natural na região do estudo. Somado a isso, a abundância de indivíduos pertencentes a espécies exóticas também foi alta (61,7\%).
A estimativa de diversidade de acordo com o Índice de Shannon H' para este estudo foi de 3,14 nats/ind., e a Equabilidade de Pielou J' 0,68, valor considerado intermediário quando comparado a outros estudos realizados no Sul do Brasil. Raber e Rebelato (2010) encontraram o índice de H’2,95 nats/ind. na cidade de Colorado/RS. Meneguetti (2003) em estudo na Orla de Santos/SP registrou índice de H’2,61 nats/ind. Bortoleto et al. (2007) obtiveram um índice de H’ 3,90 nats/ind. Lindenmaier e Santos (2008) encontraram diversidade de H’ 3,85 nats/ind. e equabilidade J' de 0.79 para as áreas verdes de Cachoeira do Sul.

Cerca de $20 \%$ dos exemplares amostrados apresentaram algum tipo de problema relacionado a podas drásticas, presença de parasitas, fitopatógenos ou conflito entre o sistema radicular e as calçadas. Entre os principais problemas que afetam a integridade da arborização viária, a poda foi o que apresentou maior frequência, afetando 15,83\% das árvores amostradas (Figura 4).

Esse número resulta, em grande parte, do plantio de espécies inadequadas aos espaços destinados, bem como o desconhecimento da população no momento do manejo, e da ausência de políticas públicas para a questão da arborização urbana. Presumivelmente, o quadro também é reflexo de aspectos socioculturais.

O conflito entre o sistema radicular das árvores e o pavimento dos passeios também constitui uma problemática à vegetação viária, ocasionado quase sempre devido à inadequação do porte das espécies inseridas no reduzido espaço das calçadas.

Entre os indivíduos amostrados foram registradas 46 árvores mortas ainda em pé (1,9\% das amostras). Pelas observações sistemáticas do trabalho de campo, é notória a morte de árvores resultante de podas drásticas ou tentativas de supressão do vegetal por parte da população, após a constatação 
da inadequação das características da árvore para o local onde foram inseridas. Muitos indivíduos submetidos a podas apresentaram ainda danos ocasionados por fungos fitopatógenos.

Figura 4. Principais problemas relacionados à qualidade da vegetação arbórea nas ruas de Cachoeira do Sul/RS

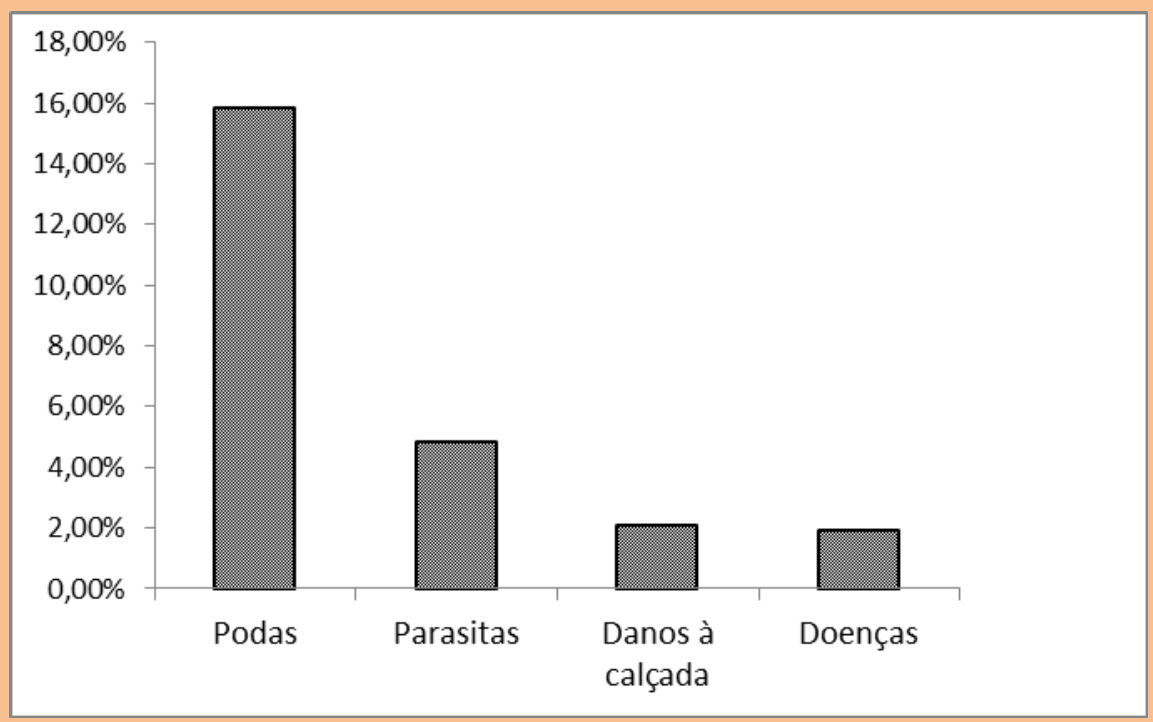

A presença de fitoparasitas registrou 5,2\% de frequência total tendo em vista o universo amostral. Tripodanthus acutifolius (Ruiz \& Pav.) Tiegh. e Phoradendron affine (DC.) Engler \& K. Krause, chamadas popularmente de Erva-de-Passarinho, foram as duas espécies de hemiparasitas identificadas parasitando indivíduos arbóreos nas ruas da cidade. $\mathrm{O}$ parasita $P$. affine foi observado vivendo predominantemente sobre indivíduos de Handroanthus chrysotrichus (Ipê-amarelo), uma espécie nativa do Cerrado brasileiro. A alta frequência desse parasita em indivíduos de Handroanthus chrysotrichus na arborização viária indica a alta especificidade entre essas duas espécies, e a possibilidade atual da ocorrência de uma infestação, o que restringiria a utilização desta espécie de Ipê na arborização de Cachoeira do Sul/RS.
A partir dos resultados obtidos através das variáveis examinadas, podemos concluir que arborização viária de Cachoeira do Sul apresenta:

- riqueza de espécies considerada de nível intermediário/alta, principalmente quando comparada a outras cidades brasileiras.
- predominância de espécies e indivíduos exóticos, com baixa presença de espécimes da flora local;

- diversidade arbórea considerada de nível intermediário;

- elevado número de indivíduos danificados por podas, bem como indivíduos mortos; 
- problemas por infestação de fitoparasitas;

- alto índice de conflitos entre o sistema radicular das plantas e o pavimento dos passeios.

\section{AGRADECIMENTOS}

Nossos sinceros agradecimentos ao PPG-Geografia UFSM, ao Geógrafo João Quoos, aos Ecólogos e Botânicos Eduardo H. Giehl e Jean Budke, a revisora de redação Ana Paula Caletti, e ao Alemão da Floricultura pelo auxílio na identificação de plantas exóticas.

\section{REFERÊNCIAS BIBLIOGRÁFICAS}

ANDRADE, T.O. Inventário e análise da arborização viária da Estância turística de Campos do Jordão, SP. 2002. 112p. il. (Dissertação de mestrado) - Escola Superior de Agricultura "Luiz de Queiroz”, Piracicaba, 2002.

ANDREATTA, T.R.; BACKES, F.A.A.L.; BELLÉ, R.A.; NEUHAUS, M.; GIRARDI, L.B.; SCHWAB, N.T.; BRANDÃO, B.S. Análise da arborização no contexto urbano de avenidas de Santa Maria, RS. Revista da Sociedade Brasileira de Arborização Urbana, Piracicaba - SP, v.6, n.1, p.36-50. 2011.

APG III. An update of the Angiosperm Phylogeny Group classification for the orders and families of flowering plants: APG III. Botanical Journal of Linnean Society, 161: 128-131. 2009.

BLUM, C.T; BORGO, M; SAMPAIO, A.C.F. Espécies exóticas invasoras na arborização de vias públicas de Maringá-PR. Revista da Sociedade Brasileira de Arborização Urbana, Piracicaba, v.3, n.2, jun. 2008, p.7897. 2008.

BORTOLETO, S. et al. Composição e distribuição da arborização viária da Estância de Águas de São Pedro SP. Revista da Sociedade Brasileira de Arborização Urbana, v.2, n.3, p.32-46, 2007.

BUCCHERI FILHO, A. T. Qualidade Ambiental no Bairro Alto da XV, Curitiba/PR. 2006, 80 f. Dissertação (Mestrado) UFPR/ Universidade Federal do Paraná. CURITIBA, 2006. Disponível em: <http://dspace.c3sl.ufpr.br/dspace/handle/1884/3773> Acesso em: 10 jan. 2012.

CAVALHEIRO, F. et al. Proposição de terminologia para o verde urbano. Boletim Informativo Sociedade Brasileira de Arborização Urbana, Rio de Janeiro: SBAU, ano VII, n.3, p.7, jul./ago./set. 1999. Disponível em: <http://www.geografia.ufpr.br/laboratorios/labs/arquivos/CAVALHEIRO\%20et\%20al\%20(1999).pdf> Acesso em: 19 jan. 2012.

CORREIA, L.R. Relação entre o critério socioeconômico e parâmetros ecológicos relativos à arborização viária de Canoas, Brasil. Pesquisas, Botânica, n. 57, p. 303-318, 2006.

CHRISTOFOLETTI, A. Modelagem de sistemas ambientais. Editora Edgard Blucher LTDA. 1 edição, São Paulo, 236p. 1999.

DALTOÉ, G. A. B.; CATTONI, E. L.; LOCH, C. Análises das Áreas Verdes do Município de São José - SC. In: Congresso Brasileiro de Cadastro Técnico Multifinalitário, Florianópolis, 2004, Anais eletrônicos. Florianópolis: UFSC, 2004. Disponível em: <http://geodesia.ufsc.br/Geodesiaonline/arquivo/cobrac_2004/066.pdf>. Acesso em: 08 jan. 2012. 
DEMATTÊ, M. E. S. P. Princípio de paisagismo. Jaboticabal: Funep, 1997.

GIEHL, E.L.H. (coordenador) 2012. Flora Digital do Rio Grande do Sul e de Santa Catarina. URL: http://ufrgs.br/floradigital

GÊISER, R. R.; OLIVEIRA, M. C. de; BRUCK, E. C.; SANTOS, J. B. DOS. Implantação de áreas verdes em grandes cidades. São Paulo: Escola Paulista de Arte e Decoração, 1976.

GREY, G. W.; DENEKE, F. J. Urban Forestry. New York: John Wiley, 1978.

GOOGLE EARTH MAPPING SERVICE. Imagens de satélite da cidade de Cachoeira do Sul. 2012. Disponível em: <http://earth.google.com/intl/pt/download.earth.html>. Acesso em: 2 out. 2012.

GONÇALVES, W. e PAIVA, H.N. Árvores para o ambiente urbano. Viçosa: Aprenda Fácil, 2004. 242 p. (Coleção Jardinagem e Paisagismo, 3).

IBGE 2011 - Instituto Brasileiro de Geografia e Estatística. Disponível em: http://www.ibge.gov.br/cidadesat/topwindow.htm?1 - Acesso em: 13.02 .12

IPAGRO, 1992. Atlas agroclimático do Rio Grande do Sul. Porto Alegre, Editora Pallotti.

ISERNHAGEN, I.; BOURLEGAT, J.M.G. e CARBONI, M. Trazendo a riqueza arbórea regional para dentro das cidades: possibilidades, limitações e benefícios. Revista da Sociedade Brasileira de Arborização Urbana, Piracicaba - SP, v.4, n.2, p.117-138, 2009.

KURIHARA, D. L.; IMAÑA-ENCINAS, J. \& de PAULA, J. E. Levantamento da arborização do campus da Universidade de Brasília. Cerne, Lavras, v. 11, n.2: 127-136. 2005.

JOSAFA, C.S.S.J. Fundamentos de uma biogeografia para o espaço urbano. Pesquisas, Botânica. São Leopoldo, n. 59: 191-210, 2008.

JUSTUS J.O.; MACHADO M.L.A. \& FRANCO M.S.M. Geomorfologia. In: IBGE(ed), Levantamento de Recursos Naturais (33). Instituto Brasileiro de Geografia e Estatística, Rio de Janeiro, p. 313 - 404. 1986.

LIMA, A. M. L.P; CAVALHEIRO, F.; NUCCI, J.C.; SOUSA, M.A.L.B.; FIALHO, N. DEL PICCHIA, P.C.D. Problemas de utilização na conceituação de termos como espaços livres, áreas verdes e correlatos. In: Anais do II Congresso de Arborização Urbana. São Luis- MA, 1994. p. 539-553.

LINDENMAIER, D.S. e SANTOS, N.O. Arborização urbana das praças de Cachoeira do Sul-RS-Brasil: fitogeografia, diversidade e índice de áreas verdes. Pesquisas, Botânica. São Leopoldo, n. 59, p. 307-320, 2008.

LOBODA, C.R e AGELIS, B.L.D. de. Áreas verdes públicas urbanas: conceitos, usos e funções. Ambiência, Guarapuava, PR, v.1 n.1, p. 125-139, jan./jun. 2005.

MAGALHÃES, L.M.S. Arborização e florestas urbanas - terminologia adotada para a cobertura arbórea das cidades brasileiras. Série Técnica, Floresta e Ambiente, p.23-26, Jan/2006. Disponível em: http://www.floram.org/files/v00n00/STv0n0a3.pdf. Acesso em: 20 de fev. 2012.

MALUF, J.R.T. et.al. Macrozoneamento agroecológico e econômico do Estado do Rio Grande do Sul. Porto Alegre: Secretaria de Agricultura e Abastecimento/Centro Nacional de Pesquisa do Trigo, v.1, 307p. 1994.

MARQUES, A.L. (coord.). Relatório Final do Inventário da Arborização Urbana do Município de Bocaina/SP. Bocaina: Instituto Internacional de Ecologia / Diretoria de Agricultura e Meio Ambiente da Prefeitura Municipal de Bocaina, 2005.

ARBORIZAÇÃO VIÁRIA DE CACHOEIRA DO SUL/RS: DIVERSIDADE, FITOGEOGRAFIA E... 
MENEGUETTI, G.I.P. Estudo de dois métodos de amostragem para inventário da arborização de ruas dos bairros da orla marítima do município de Santos-SP. Piracicaba, 2003. 100f. Dissertação (Mestrado em Recursos Florestais) - Escola Superior de Agricultura “Luiz de Queiroz”, Piracicaba, SP, 2003.

MILANO, M.; DALCIN, E. Arborização de vias públicas. 1.ed. Rio de Janeiro: LIGHT, 2000.

PAIVA, H.N. de; GONÇALVES, W. Florestas urbanas: planejamento para melhoria da qualidade de vida. Viçosa: Aprenda Fácil, 2002. 177p. (Série Arborização Urbana, 2).

PAST. Palaeontological Statistics, ver. 1.37. Øyvind Hammer, D.A.T. Harper and P.D. Ryan. November 4, 2005.

RACHID, C. e COUTO, H. T. Z. Estudo da eficiência de dois métodos de amostragem de árvores de rua na cidade de São Carlos, SP. Scientia Florestalis. São Paulo. n.56, p.59-68. 1999.

RABER, A.P. e REBELATO, G.S. Arborização viária do município de Colorado, RS - BRASIL: análise qualiquantitativa. Revista da Sociedade Brasileira de Arborização Urbana, Piracicaba - SP, v.5, n.1, p.183-199. 2010.

RUSCHEL, D. e LEITE, S.L.C. Arborização urbana em uma área da cidade de Lajeado, Rio Grande do sul, Brasil. Caderno de Pesquisa Sér. Bio., Santa Cruz do Sul, v. 14, n. 1, p. 07-24. 2002.

SALVI, L.T.; HARDT, L.P.A.; ROVEDDER, C.E.; FONTANA, C.S. Arborização ao longo de ruas - Túneis Verdes - em Porto Alegre, RS, Brasil: avaliação quantitativa e qualitativa. Revista Árvore, Viçosa-MG, v.35, n.2, p.233-243. 2011.

SANTAMOUR JÚNIOR, F.S. Trees for urban planting: diversity uniformity, and common sense. In: METRIA CONFERENCE, 7., 1990, Lisle. Proceedings. Lisle: p.57-66. 1990.

SANTOS, N.R.Z dos; TEIXEIRA, I.F. Arborização de vias públicas: ambiente x vegetação. Santa Cruz do Sul: Instituto Souza Cruz, 135p. 2001.

SHINZATO, P. O impacto da vegetação nos microclimas urbanos. São Paulo, 2009. 173f. Dissertação (Mestrado em Arquitetura e Urbanismo) USP-São Paulo, SP, 2009.

SOUZA, V.C. e LORENZI, H. Botânica sistemática: guia para identificação das famílias de Angiospermas da flora brasileira, baseado em APG II. Nova Odessa, SP: Instituto Plantarum, 640 p. 2005.

SOUZA, A.M. de; NACHTERGAELE, M.F. e CARBONI, M. Inventário Florestal da arborização do município de Jaú/SP. Jaú: Instituto Pró-Terra \& Secretaria do Meio Ambiente - SEMEIA. Relatório técnico, 2004.

TEIXEIRA, M. B.; COURA NETO, A. B.; PASTORE, U. e RANGEL FILHO, A. L. R. Vegetação In: Levantamento de recursos naturais (33). Rio de Janeiro, Instituto Brasileiro de Geografia e Estatística, p. 541632. 1986.

UNFPA. Relatório do Fundo de População das Nações Unidas 2011. Disponível em: http://www.unfpa.org.br/novo/ - Acesso em: 21 dez. 2011.

W3TROPICOS - Banco de dados do Missouri Botanical Garden. Disponível em: www.tropicos.org. Acesso em 12 junho de 2012. 